\title{
Impact of Chronic Protein-Calorie Malnutrition on Small Intestinal Repair after Acute Viral Enteritis: A Study in Gnotobiotic Piglets ${ }^{1}$
}

\author{
J. DECKER BUTZNER, DANIEL G. BUTLER, O. PAUL MINIATS, AND J. RICHARD HAMILTON
}

Department of Clinical Studies, University of Guelph, Guelph and Division of Gastroenterology, Department of Pediatrics, University of Toronto, Research Institute, The Hospital for Sick Children, Toronto, Ontario, Canada

\begin{abstract}
To investigate the effect of chronic proteincalorie malnutrition on intestinal repair after an enteric infection, we examined small intestinal structure, enzyme activity, and sodium transport in undernourished piglets during the acute and convalescent phases of a viral enteritis, transmissible gastroenteritis (TGE). Gnotobiotic pigs, nutritionally deprived from the age of 7 days, gained less weight than dietary controls from 14 days of age until the end of the study. Animals from malnourished and control diet groups were innoculated with TGE virus at 22-23 days and studied during the acute $(40 \mathrm{~h})$ and convalescent (4, 10 , and 15 days) stages of this experimental enteritis along with noninfected dietary controls. After TGE infection, we observed a further decrease in weight gain and an increased mortality only in undernourished pigs. In jejunum and ileum of both dietary groups at $40 \mathrm{~h}$ after TGE infection, we observed comparable structural lesions, similar decreased activities of mucosal enzymes (sucrase, lactase, sodium-potassium-dependent ATPase), and increased thymidine kinase activities. Also we noted comparable diminution of glucose-stimulated jejunal sodium absorption in both dietary groups at $40 \mathrm{~h}$. In control diet pigs, transport abnormalities recovered by 4 days after TGE infection and normal mucosal structure and enzyme activity returned over 4-15 days. In undernourished piglets, structural repair and enzyme abnormalities were prolonged when compared with the control diet group; glucose-stimulated sodium transport did not recover until 10 days after infection and never regained the enhanced activity seen in noninfected undernourished controls. We conclude that small intestinal recovery of the undernourished animal after viral enteritis is prolonged and speculate that impaired mucosal repair is important determinant of the delayed recovery of structural and functional abnormalities in this animal model of a major human disease. (Pediatr Res 19: 476-481, 1985)
\end{abstract}

\section{Abbreviations}

$I_{\text {sce }}$, short circuit current

$\mathbf{J}_{\mathbf{m} \rightarrow \mathbf{s}}^{\mathrm{Na}}$, mucosa to serosa sodium flux

$\mathbf{J}_{\mathbf{s} \rightarrow \mathbf{m}}^{\mathbf{N a}}$, serosa to mucosa sodium flux

$\mathbf{J}_{\text {net, }}^{\mathrm{Na}}$, net sodium flux

Na-K-ATPase, sodium-potassium-dependent ATPase

Received October 25, 1984; accepted January 16, 1985.

Reprint requests: Dr. J. R. Hamilton, Division of Gastroenterology, The Hospital for Sick Children, 555 University Avenue, Toronto, Ontario, Canada, M5G 1X8.

Supported by grants from the Medical Research Council of Canada, the Diarrheal Disease Control Program of the World Health Organization and the Physicians Services Incorporated Foundation.

${ }^{1}$ Presented in part at the Annual Meeting of the Canadian Society for Clinical Investigation, Calgary, Alberta, 1983.
$P D$, potential difference

TGE, transmissible gastroenteritis

Of the millions of annual infant deaths attributed to infectious diarrhea, most occur in regions where malnutrition is prevalent (1). Epidemiological studies suggesting that diarrhea may be prolonged in the malnourished host (2-4) provide little insight into the nature of any interactions between enteric infection and protein-calorie malnutrition. Such insight is needed if improvements in treatment of this major health problem are to occur. In piglets, experimentally infected with a specific enteric viral pathogen, we compared the course of disease in animals subjected to chronic protein-calorie deprivation with normally nourished controls. Because both enteritis and chronic undernutrition are known to influence the small intestinal epithelium (5-9), we focused our studies on the structure and function of that organ. Our hypothesis was that after acute viral injury to the small intestinal mucosa, epithelial repair would be delayed in the undernourished host. Our findings support that hypothesis.

\section{METHODS}

All experiments used gnotobiotic (germ-free) piglets because of the recognized vulnerability to intercurrent infection of conventional piglets, when undernourished. Seventy York-Landrace piglets from nine litters were delivered by cesarean section, placed in gnotobiotic isolators, and raised according to the Ontario Veterinary College gnotobiotic protocol (10). Initially, all piglets were fed evaporated cow's milk and given injections of selenium vitamin E, and iron-dextran at previously standardized times. At 7 days of age, they were randomly assigned to control or undernourished dietary groups. Control animals continued to receive evaporated cow's milk in daily increasing increments of $12 \%$, based on an initial volume of $138 \mathrm{ml} / \mathrm{kg} /$ day calculated on day 7. The undernourished group also was fed an evaporated cow's milk formula, diluted to maintain the volume and electrolyte content equivalent to the control diet, but with a protein, fat, and carbohydrate density of $50 \%$ of controls. The volumes of the feeds were increased daily for 16 days (day 7-23). On day 22 or 23 , randomly selected groups of piglets received by gastric tube, $0.5 \mathrm{ml}$ of a bacteria-free suspension of the Purdue strain of TGE virus (5). A pilot study had established this dose as one that induced infection in animals of both dietary groups, yet permitted survival and recovery. Therefore, after infection, there were four study groups: noninfected and infected pigs receiving the control diet and noninfected and infected pigs receiving the depleted diet. Dietary volumes were held constant for the re- 
mainder of the study in all groups. All animals received an oral glucose-electrolyte rehydration solution for $48 \mathrm{~h}$ after TGE infection, or for an equivalent period in the case of noninfected controls. The diet was then advanced to half-strength of each group's original formula for an additional 4 days. By 6 days after infection, or 29 days of age, all piglets once again received their respective control or depleted diets.

We measured animal weights weekly before infection and every 2-3 days after infection. We studied infected animals at 40 h (acute diarrhea), 4 days (early convalescence), 10 and 15 days (late convalescence) after infection, and noninfected controls at comparable times. Initially, the noninfected animals in each dietary group were age-matched with infected animals. Because we found no age-related variability of intestinal function or structure over the 19-day study period, data from noninfected animals of all ages (23-41 days) were combined into control diet or undernourished groups and compared with infected animals at each stage after the infection. Bacterial cultures from rectal swabs were used to monitor contamination of the animals in the 1st wk of life, immediately prior to infection with TGE, and when the animals were killed. Contamination occurred in $37 \%$ of the animals; the incidence did not differ significantly between the two dietary groups or between those infected and those not infected with TGE virus. In each instance, monocontamination with a bacterium (lactobacillus, Streptococcus viridans, Staphylococcus epidermis or bacteroides supp.) not pathogenic to the gastrointestinal tract was noted.

For intestinal studies, animals were killed with $325 \mathrm{mg}$ of sodium pentabarbital given parenterally. Blood was collected at the time of death for measurement of hematocrit, sodium, potassium, chloride, urea, total protein, and albumin concentrations, all of which remained within the normal range throughout the study in all groups. The proximal $52 \mathrm{~cm}$ of jejunum, beginning $10 \mathrm{~cm}$ distal to the ligament of Treitz was quickly removed and flushed with ice-cold isotonic saline. The upper $40 \mathrm{~cm}$, stripped of serosal and muscular layers, were used for ion transport studies and the remaining $12 \mathrm{~cm}$ for light and transmission electron microscopic and enzyme studies. A $12-\mathrm{cm}$ piece of ileum, starting $10 \mathrm{~cm}$ above the ileocecal sphincter was also removed for microscopic and enzyme studies. The remainder of the small intestine was flushed and weighed.

Tissue for light microscopy was fixed overnight in Bouin's fixative, resuspended in $95 \%$ alcohol, embedded in paraffin, and sectioned and stained with hematoxylin-eosin. Coded sections were examined by one observer (JDB) without prior identification of the section, using a calibrated micrometer to measure villus height and crypt depth in 10-15 properly oriented cryptvillus units. Epithelial injury was semiquantified; sections containing uniformly columnar cells with basal nuclei and distinct brush borders were considered normal and sections containing cuboidal cells with central nuclei, poorly defined brush borders, and a flattened mucosal surface were considered abnormal. Tissue for transmission electron microscopy was fixed with glutaraldehyde and embedded in epon.

For enzyme analyses, a 10-cm segment of intestine was opened, the mucosa scraped off with a glass slide, homogenized in 2.5 mM EDTA, adjusted to $\mathrm{pH} 7.5$ with Tris, in a glass homogenizer $(100 \mathrm{mg} / \mathrm{ml})$, quick frozen, and stored at $-80^{\circ} \mathrm{C}$ until the time of assay. Sucrase and lactase activities were determined by the method of Dahlquist (11), Na-K-ATPase activity by the method of Kelly et al. (12), thymidine kinase activity by a modification (7) of the method of Klemperer and Haynes (13) and protein content by the method of Lowry (14).

For ion transport studies, eight adjacent segments of stripped jejunal mucosa were mounted in short-curcuited Ussing chambers, using techniques previously described from this laboratory (8). In four chambers, the tissues were bathed in oxygenated Krebs-bicarbonate buffer at $37^{\circ} \mathrm{C}$ and $\mathrm{pH} 7.4 \pm 0.1$; in the other four, the buffer also contained $30 \mathrm{mM}$ glucose. One $\mathrm{ml}$ of buffer, containing 6.7 $\mu \mathrm{Ci}^{22} \mathrm{Na}$ (Amersham, Willowdale, Ontario, Can- ada), was added to either the mucusal or serosal side of each tissue segment. After a 15-min equilibration period, samples were obtained from the mucosal and serosal chambers at $10-\mathrm{min}$ intervals over the next $40 \mathrm{~min}$. Steady state unidirectional, mucosa to serosa $\left(J_{m \rightarrow s}^{\mathrm{Na}}\right)$ serosa to mucosa $\left(J_{s \rightarrow m}^{\mathrm{Na}}\right)$ and net $\left(J_{\text {net }}^{\mathrm{Na}}\right)$ sodium fluxes $\left(\mu \mathrm{Eq} / \mathrm{cm}^{2} / \mathrm{h}\right)$ were measured in paired tissues in the absence of an electrochemical gradient across the tissue as previously described (8). We monitored transmucosal potential difference (PD) at 10-min intervals and the short-circuit current $\left(\mathrm{I}_{\mathrm{sc}}\right)$ needed to neutralize the electrical gradient was applied with an adjustable current source. Conductance was calculated from $\mathrm{PD}$ and $\mathrm{I}_{\mathrm{sc}}$ readings.

Statistical comparisons were made using Student's unpaired $t$ test; for the enzyme data analyses, a logarithmic distribution was assumed and results analyzed as logarithms and expressed as antilogarithms. We analyzed mortality and contamination data by the $\chi^{2}$ method.

\section{RESULTS}

General Response of Piglets to Diet and Infection. None of the control diet group died, but five of 26 undernourished animals died between 2 and 9 days after TGE infection; this difference between dietary groups was significant. Persistent diarrhea, unresponsive to fluid therapy, caused severe dehydration in the five fatal cases and bacteria could be cultured from only one of these animals. Data from the animals that died were not included in any of the analyses summarized below.

Body weights for the two dietary groups did not differ on day 7 , at the time the experimental diet was begun $(1.47 \pm 0.04 \mathrm{~kg}$ versus $1.48 \pm 0.03 \mathrm{~kg}$, mean \pm SEM) but by day 14 of life, having received the experimental diet for only 7 days, the undernourished piglets $(1.96 \pm 0.05 \mathrm{~kg})$ weighed significantly less than controls $(2.26 \pm 0.06 \mathrm{~kg}, p<0.001)$. Mean cumulative weight gain was also significantly less in undernourished animals than in controls from day 14 onward (Fig. 1). By 8 days after experimental TGE infection, when the pigs were 31 days of age and diarrhea had ceased, the weight gained by infected undernourished piglets $(1.58 \pm 0.09 \mathrm{~kg})$ was significantly less than that gained by noninfected undernourished piglets $(2.05 \pm 0.11 \mathrm{~kg}, p$ $<0.01$ ) despite an equivalent nutrient intake. This reduced rate of gain persisted in undernourished pigs after TGE infection for the remainder of the study (Fig. 1). In contrast, weight gain did not differ between infected and noninfected control diet animals throughout the study.

Small intestinal weight per $\mathrm{kg}$ body weight in noninfected pigs did not differ between undernourished $(36.7 \pm 1.8 \mathrm{~g} / \mathrm{kg})$ and control diet $(37.5 \pm 1.2 \mathrm{~g} / \mathrm{kg})$ groups. Forty hours after infection, when the pigs had acute diarrhea, gut weight relative to body weight fell significantly below that of noninfected controls $(p<$ 0.001 ) in both dietary groups, $23.4 \pm 0.4 \mathrm{~g} / \mathrm{kg}$ for undernourished and $24.7 \pm 1.0 \mathrm{~g} / \mathrm{kg}$ for the control diet pigs. By 4 days after infection, gut weight had returned to values of noninfected animals in both dietary groups.

Intestinal Response to Diet and Infection. Microscopic findings. Villus height, crypt depth, and epithelial cell appearance in jejunum and ileum were similar for noninfected pigs in the two dietary groups (Fig. 2). In jejunal sections from undernourished pigs, $40 \mathrm{~h}$ and 4 days after TGE infection, significant villus blunting was noted and cuboidal epithelial cells were seen on villi; these abnormalities were present only at $40 \mathrm{~h}$ after infection in control diet pigs. Also, in the undernourished animals, significant jejunal crypt elongation persisted from 4 through 15 days after infection, while in the control diet group we noted this elongation only at 4 days. In ileal sections from undernourished animals after TGE infection, the epithelium was cuboidal and villus height was significantly decreased at $40 \mathrm{~h}$ and at 4 and 10 days, returning to normal by 15 days; elongated crypts appeared at 4 days and persisted throughout the remainder of the study in the undernourished group (Fig. 2). In contrast, ileal villus height 


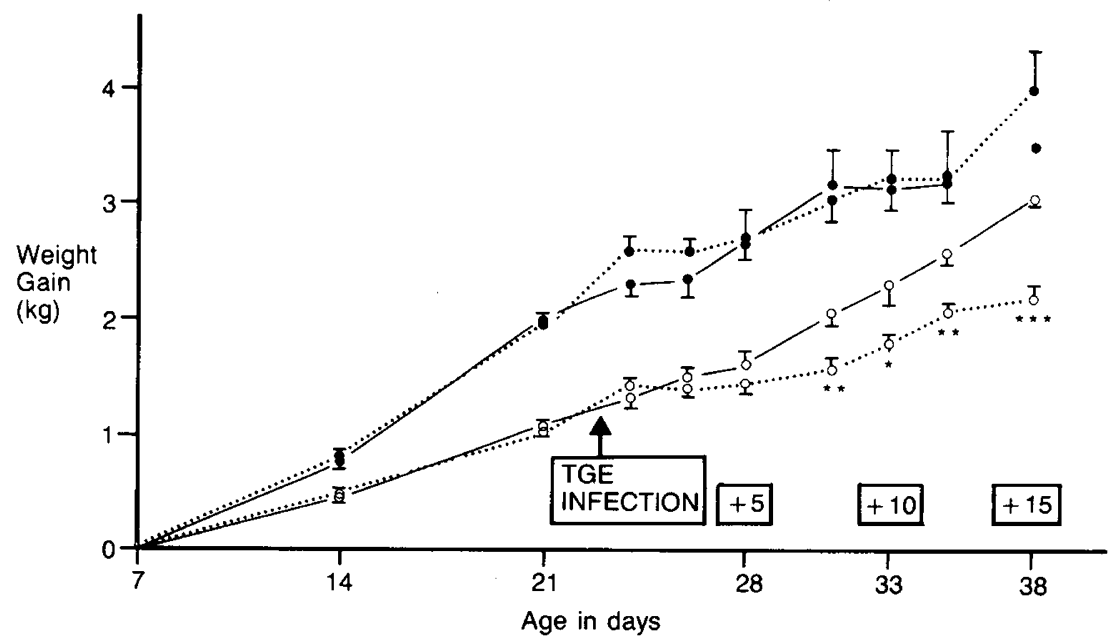

Fig. 1. Mean cumulative weight gains of gnotobiotic pigs. Animals undernourished $(O)$ from age 7 days gained less than control diet pigs $(\bullet)$ at all time periods from 14 days $(p<0.01)$. Pigs infected with TGE virus (broken lines) at 22-23 days compared with noninfected pigs (solid lines) in same dietary group, (Mean $\pm \mathrm{SEM},{ }^{*} p<0.05,{ }^{* *} p<0.01,{ }^{* * *} p<0.001$ ). Numbers in squares refer to days after TGE infection.

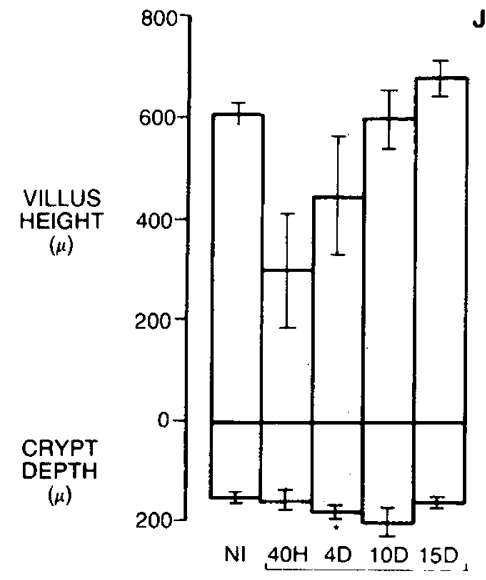

JEJUNUM

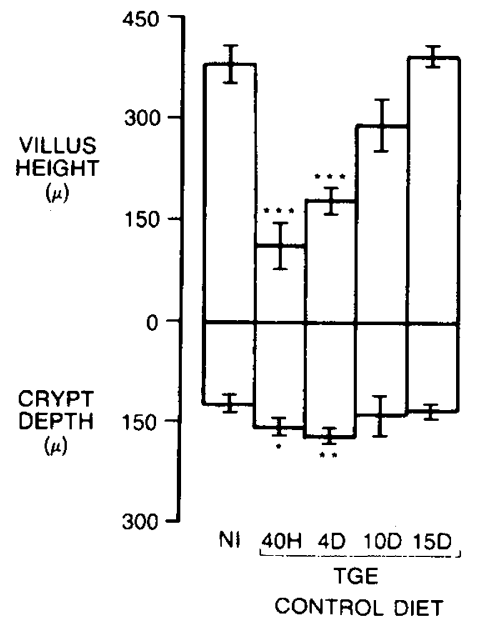

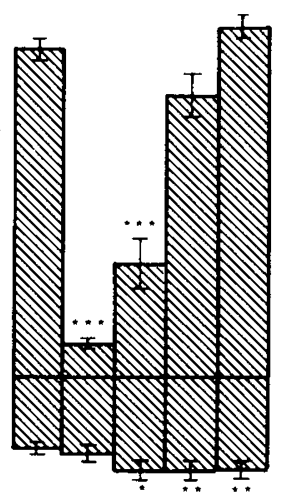

$\mathrm{NI} \quad 40 \mathrm{H} \quad 4 \mathrm{D} \quad 10 \mathrm{D}$ 15D,

ILEUM

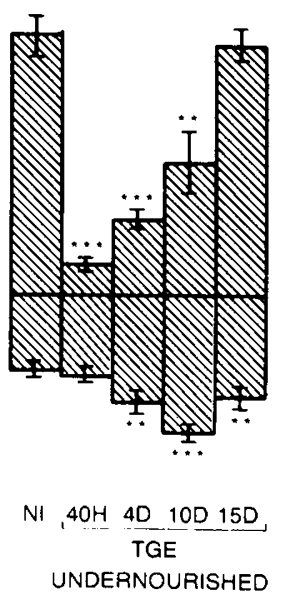

Fig. 2. Jejunal and ileal mucosal structure in control diet and undernourished groups. Piglets $40(40 \mathrm{H}), 4$ days $(4 \mathrm{D}), 10$ days $(10 \mathrm{D})$, or 15 days $(15 \mathrm{D})$ after experimental TGE infection compared with noninfected piglets $(N I)$ in same dietary group (mean $\pm \mathrm{SEM},{ }^{*} p<0.05,{ }^{* *} p$ $<0.01,{ }^{* * *} p<0.001$ ).

and crypt depth along with the epithelial cells were abnormal only at $40 \mathrm{~h}$ and 4 days after infection in control diet pigs. No viral particles were identified in small intestinal sections by electron microscopy at any of the study periods after TGE infection in pigs from either diet group.

Mucosal enzyme activities. Although dietary deprivation alone caused no alteration of the activities of the jejunal mucosal enzymes measured (Table 1), we found a significant elevation of lactase activity and a significant depression of Na-K-ATPase activity in the ileum (Table 2) of noninfected undernourished piglets compared with normally nourished controls.

Mean jejunal mucosal sucrase activities measured $40 \mathrm{~h}$ after TGE infection were significantly less than those measured before infection in both dietary groups (Table 1). This abnormality was noted at 4 and 15 days in the undernourished animals, but only at 10 days in the control diet group. Also, in the undernourished group lactase and Na-K-ATPase activities, reduced at $40 \mathrm{~h}$, remained significantly depressed throughout the entire 15-day study period after infection. In contrast, the control diet group's jejunal lactase activity, while similarly reduced at $40 \mathrm{~h}$, had returned to normal by 10 days after infection and Na-K-ATPase activity was never significantly depressed after TGE infection. Thymidine kinase activity, a marker of immature crypt-type DNA-producing cells (7), was significantly elevated in jejunal mucosa by $40 \mathrm{~h}$ after infection in both dietary groups, returning to normal by 10 days in the undernourished animals and by 15 days in controls.

In the ileal mucosa of undernourished pigs, lactase and sucrase activities which were significantly depressed $40 \mathrm{~h}$ after infection, never returned to the level of noninfected pigs during the 15-day study period (Table 2). In the control diet group, ileal lactase and sucrase activities returned to noninfected values by 10 days and 15 days after infection, respectively. Ileal mucosal Na-KATPase activity in the undernourished piglets $40 \mathrm{~h}$ after infection was significantly less than that of undernourished noninfected piglets and it remained significantly depressed until 15 days after infection when compared with noninfected control diet animals. In control diet pigs, ileal Na-K-ATPase activity had returned to noninfected levels by 10 days after infection. Ileal thymidine kinase activity was significantly elevated in both dietary groups $40 \mathrm{~h}, 4$ and 10 days postinfection. However, in the undernourished animals, it gradually rose at $40 \mathrm{~h}$ and 4 days, peaking at 10 days after infection, while in control diet animals, this peak occurred sooner, $40 \mathrm{~h}$ after infection.

Jejunal sodium transport. Table 3 summarizes jejunal unidirectional and net $\mathrm{Na}$ flux data in short-circuited Ussing chambers for the four study groups. In noninfected animals under basal conditions, unidirectional sodium fluxes were significantly greater in undernourished animals compared with normally nourished controls $\left(\mathrm{J}_{\mathrm{m} \rightarrow \mathrm{s}}^{\mathrm{Na}}, p<0.001 ; \mathrm{J}_{\mathrm{s} \rightarrow \mathrm{m}}^{\mathrm{Na}}, p<0.01\right)$, while net fluxes remained equivalent in the two dietary groups. The addition of $30 \mathrm{mM}$ glucose stimulated a significant increment of net 
Table 1. Enzyme activities: piglet jejunal mucosal homogenates

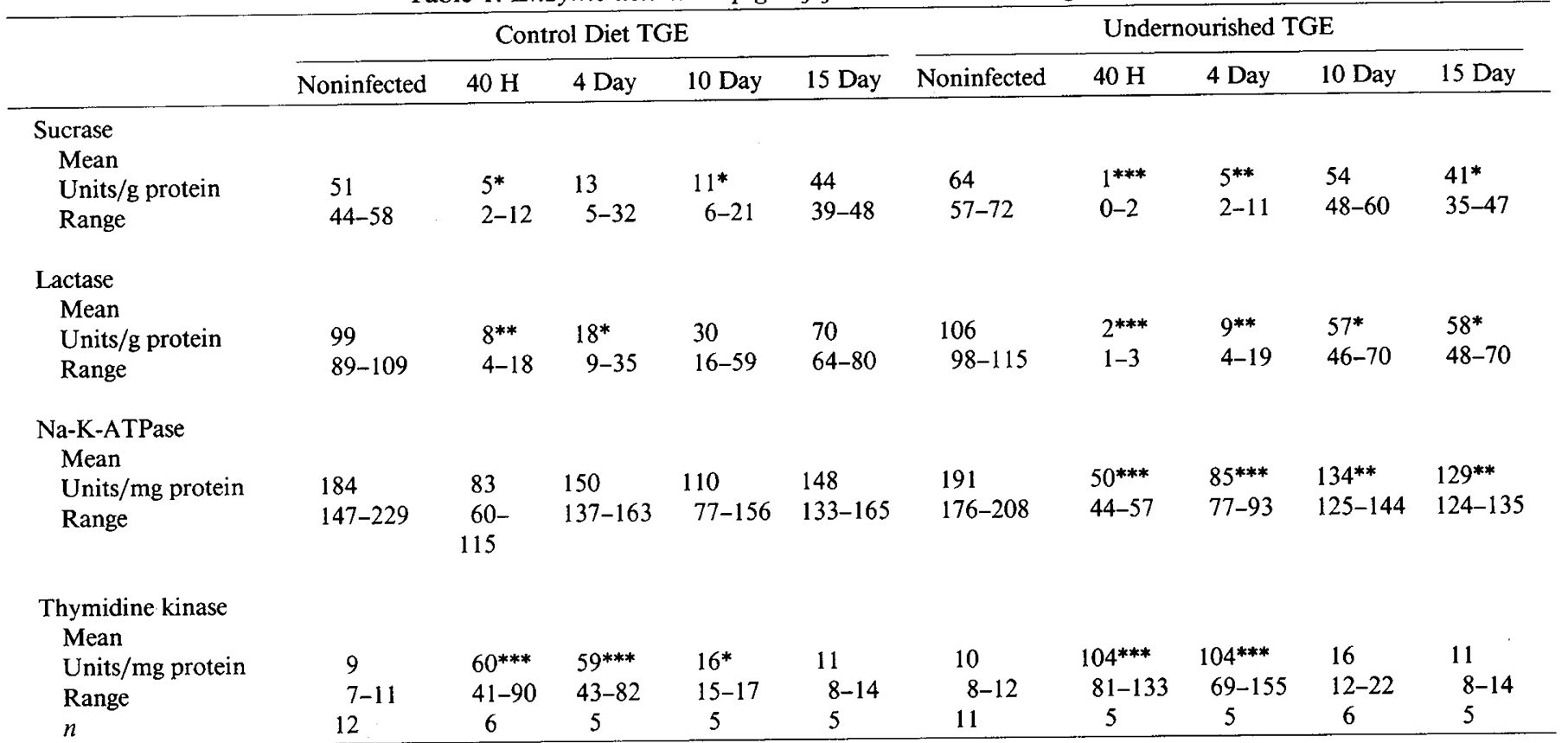

Results expressed as antilog mean and range of 1 SEM where $n=$ number of animals.

${ }^{*} p<0.05 ;{ }^{* *} p<0.01 ;{ }^{* * *} p<0.001$ postinfection value compared with noninfected in same dietary group.

Table 2. Enzyme activities: piglet ileal mucosal homogenates

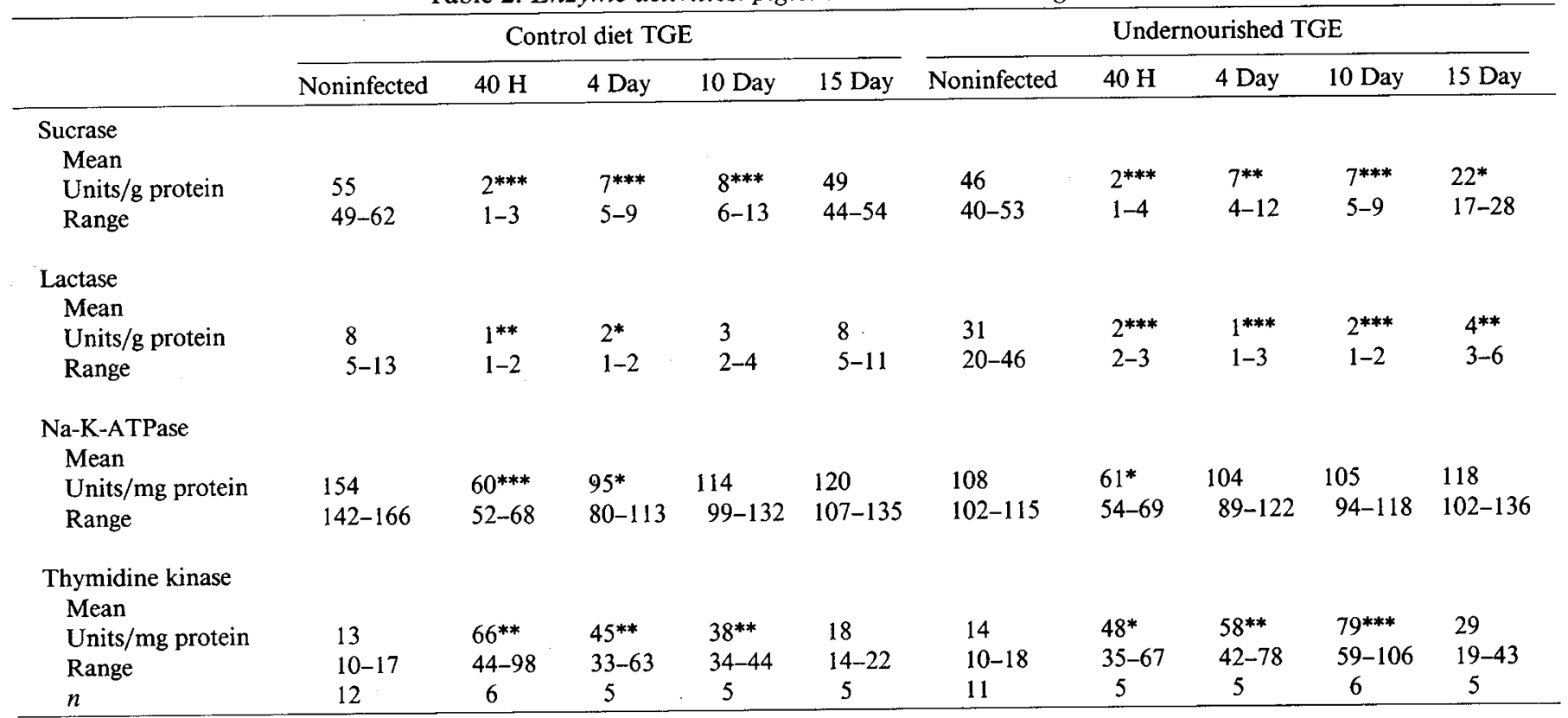

Results expressed as antilog mean and range of 1 SEM where $n=$ number of animals.

${ }^{*} p<0.05 ;{ }^{* *} p<0.01 ;{ }^{* * *} p<0.001$ postinfection value compared with noninfected in same dietary group.

sodium absorption above basal levels in noninfected piglets in both dietary groups; this enhancement of net sodium absorption was significantly greater in the undernourished group $(+8.9 \pm$ $\left.1.1 \mu \mathrm{Eq} / \mathrm{cm}^{2} / \mathrm{h}\right)$ than in the control diet group $(+4.9 \pm 0.8 \mu \mathrm{Eq} /$ $\left.\mathrm{cm}^{2} / \mathrm{h}, p<0.01\right)$. The addition of glucose caused a significant increment in both $\mathrm{J}_{\mathrm{m} \rightarrow \mathrm{s}}^{\mathrm{Na}},(20.7 \pm 1.1$ versus $13.3 \pm 0.8, p<$ $0.0001)$ and $\mathrm{J}_{\mathrm{s} \rightarrow \mathrm{m}}^{\mathrm{Na}},(11.8 \pm 0.5$ versus $8.4 \pm 0.4, p<0.001)$ in noninfected undernourished animals compared with noninfected controls, but it was the marked increase in mucosal to serosal flux that provided the main contribution to the significant increase in net absorption. In the noninfected groups, PD, $\mathrm{I}_{\mathrm{sc}}$, and conductance were all significantly elevated in the undernourished animals compared with the control diet group (Fig. 3).
Forty hours after TGE infection, glucose did not stimulate sodium absorption in tissue from either dietary group. By 4 days after TGE infection, sodium absorption in the jejunum from control diet animals once again increased significantly with the addition of $30 \mathrm{mM}$ glucose. In contrast, no significant glucose stimulation of sodium flux was noted in the undernourished piglets' jejunal epithelia at this 4-day stage of infection; by 10 days, significant glucose-stimulated sodium transport was observed in both control diet and undernourished piglets. However, even by 15 days after infection, undernourished animals still had not regained the enhanced glucose-stimulated mucosal to serosal $(12.2 \pm 0.7$ versus $20.7 \pm 1.1, p<0.001)$ or net $(+5.6 \pm 0.7$ versus $+8.9 \pm 1.1, p<0.05)$ sodium absorptive capacity observed 
Table 3. Sodium flux in short-circuited jejunal epithelium in control diet and undernourished piglets $\left(\mu E q / \mathrm{cm}^{2} / \mathrm{h}\right)$

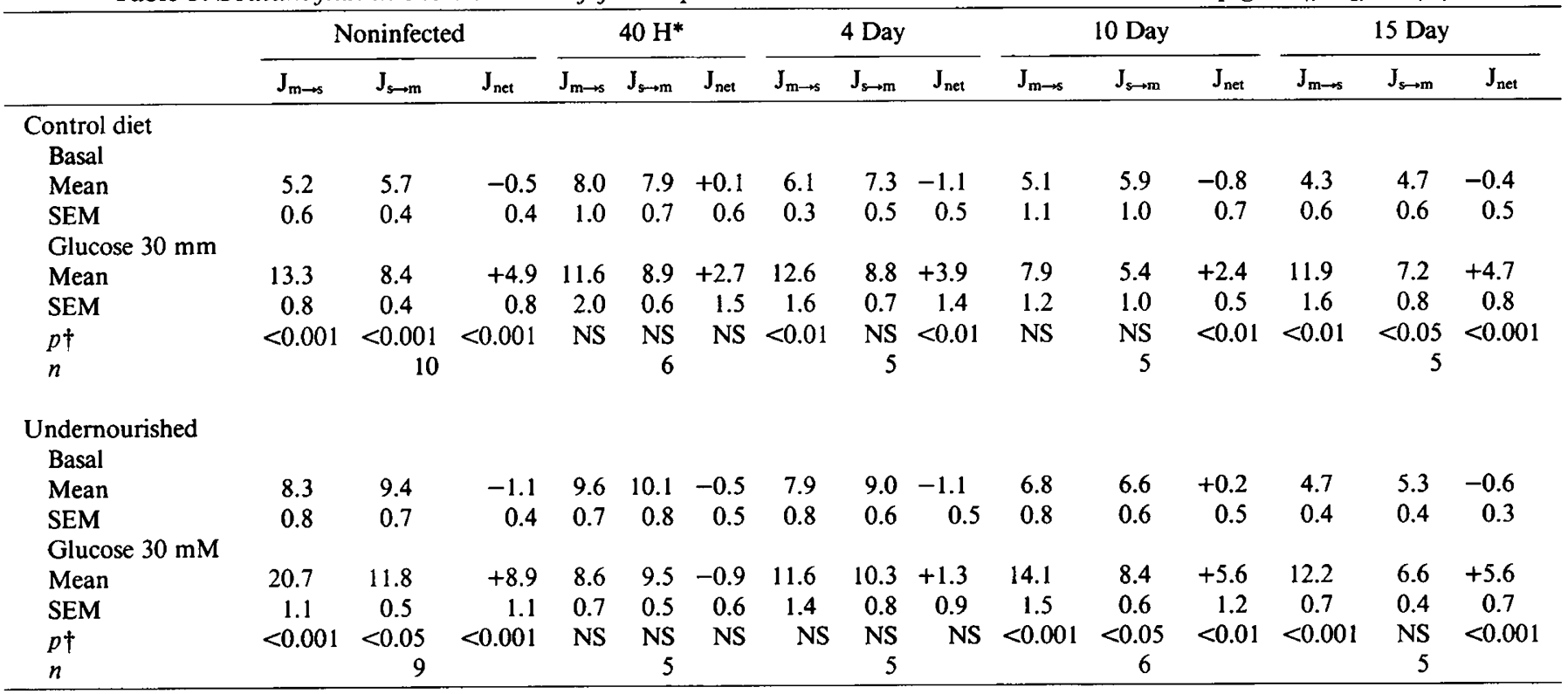

* Time after TGE viral infection.

† Values in the presence of $30 \mathrm{mM}$ glucose compared with basal values.
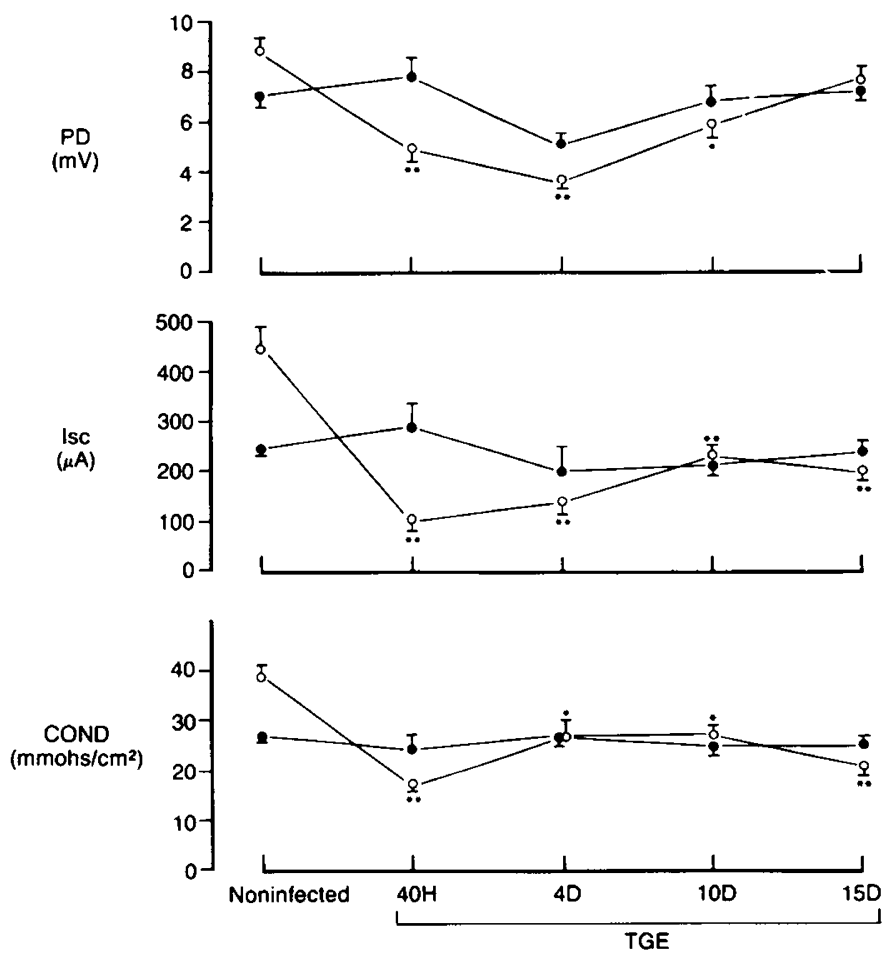

Fig. 3. Piglet jejunal epithelial transmucosal $P D, I_{s c}$, and conductances $(C O N D)$ in presence of $30 \mathrm{mM}$ glucose in control diet $(\Theta)$ and undernourished $(O)$ animals. PD $(p<0.01), \mathrm{I}_{s c}(p<0.001)$, and COND $(p<0.001)$ significantly elevated in noninfected undernourished animals compared with noninfected animals on the control diet. Piglets $40 \mathrm{~h} \mathrm{(40}$ $H$ ), 4 days $(4 \mathrm{D}), 10$ days $(10 \mathrm{D})$, or 15 days $(15 \mathrm{D})$ after experimental TGE infection compared with noninfected piglets in same dietary group (mean $\left.\pm \mathrm{SEM},{ }^{*} p<0.01,{ }^{* *} p<0.001\right)$.

in noninfected undernourished controls. $\mathrm{PD}, \mathrm{I}_{\mathrm{sc}}$, and conductance of jejunal tissue from control diet animals did not differ between noninfected and infected animals in the basal period or with the addition of $30 \mathrm{mM}$ glucose (Fig. 3). In the undernourished group after TGE infection, PD remained significantly depressed until 15 days after infection, when compared with noninfected undernourished controls in the presence of $30 \mathrm{mM}$ glucose. $I_{s c}$ and conductance did not return to the level of noninfected undernourished controls throughout the study.

\section{DISCUSSION}

Our data clearly demonstrate that in nutritionally deprived gnotobiotic pigs, the structural and functional lesion of the small intestinal mucosa is prolonged after infection with TGE virus. Also deaths occurred after TGE infection only in undernourished animals. Evidence of a reciprocal relationship between enteric infection and malnutrition emerges from our model, in that TGE infection itself led to a further reduction in weight gain in the nutritionally deprived group. Since infected and noninfected piglets received identical nutrient intakes, this latter finding suggests that either altered utilization or excessive losses of nutrients occurred after TGE infection in the malnourished host.

Limitation of nutrient intake over the 15- to 16-day interval before experimental viral infection produced a state of chronic undernutrition as reflected in proportionate and significantly diminished body weight gain. Although severe morphological abnormalities and depressed activities of disaccharidases of the small intestine have been described in clinical studies of malnutrition $(15,16)$, these field studies have not distinguished the direct effects of nutritional deficiency from those of other possible coincidental intestinal diseases such as enteric infections. In Brunser's study of marasmic infants (17) and Neutra's examination of tetracycline-treated, protein-calorie malnourished pigs (18), the light microscopic structure of the small intestinal mucosa was normal with the exception of a mild decrease in thickness and a relative reduction of mitotic figures in the epithelium. In our undernourished noninfected piglets, we also demonstrated a preservation of small intestinal weight relative to body weight, of mucosal structure, and of most mucosal enzyme activities when compared with noninfected dietary controls. The high activity of lactase seen in nutritionally deprived pigs, also noted in other animal models of early chronic malnutrition, has been attributed to a delay in postnatal maturation of the small intestinal epithelium $(6,19)$; the depressed activity of ileal $\mathrm{Na}-\mathrm{K}-\mathrm{ATPase}$ in the undernourished pigs could have a similar basis (20).

The jejunal mucosa of the noninfected undernourished piglets was relatively porous since unidirectional sodium fluxes and 
electrical conductance were high in this tissue. A similar large low resistance paracellular ion flux also has been noted in young suckling rabbits (20), suggesting that this relative porosity may be a feature of immaturity. However, in another respect, ion transport in the malnourished piglet intestine seems to differ from that of the immature rabbit where glucose fails to stimulate sodium absorption. Glucose-stimulated sodium absorption in the jejunum of malnourished pigs was enhanced along with mucosa to serosa sodium flux, PD, $\mathbf{I}_{\text {sc }}$, and conductance when compared with heavier controls. Previous studies of acute nutrient deprivation have demonstrated increased net ileal sodium absorption in pigs (21) and increased active glucose transport in rats and guinea pigs (22). The mechanisms for this unexpected observation of enhanced sodium transport in our model of chronic undernutrition are unknown but clearly they are not attributable only to paracellular phenomena.

Several explanations for the observed delay in recovery from viral intestinal injury in malnourished piglets should be considered. Since viral particles were not observed in the small intestinal mucosa of the malnourished animals, we conclude that prolongation of this invasive but normally transient viral infection was not an important factor. Previous studies of TGE in conventional piglets have also demonstrated rapid shedding of the virus from the intestinal mucosa in the first $40 \mathrm{~h}$ after infection $(23,24)$. Although the undernourished pig is likely to have compromised immune function and consequently, increased susceptibility to infection, enteric bacteria did not appear to be important determinants of the prolonged disease course of the nutritionally deprived group. Bacteria were isolated from a similar proportion of the two dietary groups of pigs that were initially germ free, and none was an organism known to have any effect on small intestinal function or structure.

Prolongation of the lesion in malnourished pigs could have resulted from delayed epithelial repair after viral injury, increased severity of the initial injury, or a combination of these factors. The undernourished animal, in theory, may have compromised barrier function to a viral pathogen, and therefore sustain an initial injury of relatively increased severity. However, our findings in 40-h TGE-infected malnourished pigs demonstrate no differences from 40-h infected control diet animals in mucosal structure, enzyme function, or transport function. In fact, the only significant diet-related differences found at the acute stage of TGE were in the electrical properties of the tissue in Ussing chambers with $\mathrm{PD}, \mathrm{I}_{\mathrm{sc}}$, and conductance being lower in the undernourished group. A well-recognized effect of chronic protein-calorie malnutrition on the small intestine is impairment of epithelial proliferation in crypts resulting in delayed cellular migration along the crypt-villus axis (6). Theoretically this abnormality of epithelial renewal might retard repair after the TGE-induced villus cell injury. The prolonged abnormalities of mucosal structure, delayed return of the brush border disaccharidases along with basolateral membrane Na-K-ATPase, and delayed recovery of glucose-stimulated sodium absorption in undernourished piglets after TGE infection, support this hypothesis. In addition, glucose-stimulated sodium transport in infected undernourished piglets never regained the enhanced activity seen in the undernourished but noninfected group.

Our findings point to the small intestinal epithelium and its renewal as a site for important interactions between undernutrition and viral enteritis, a major cause of infant diarrhea. These interactions continue to be vitally important to infants throughout the world. Because of uncontrollable variables operative in most clinical settings where these issues might be subjected to field studies, animal-based experiments will continue to play an important part in sorting out the malignant cycle that associates diarrhea and malnutrition in babies.

Acknowledgments. The authors thank Dr. Mary Perdue and Dr. John Baird for helpful suggestions; Wilson Chan, Mahmood Kahn, Chris Lewis, Lynn Rini, Helen Rooyakkers, Krys Streich, William Wilson, Brian Bloomfield, and Maria Nadvornik for expert technical assistance, and Mrs. Jill Lennox for secretarial help.

\section{REFERENCES}

1. Rohde JE, Northrup RS 1976 Taking science where the diarrhea is. In: Acute Diarrhea in Childhood, Ciba Foundation Symposium, 42. Elsevier, Oxford, pp 339-366

2. Black RE, Brown $\mathrm{KH}$, Becker S 1984 Malnutrition is a determining factor in diarrheal duration, but not incidence among young children in a longitudinal study in rural Bangladesh. Am J Clin Nutr 39:87-94

3. Palmer DL, Koster FT, Alam AKMJ, Islam MR 1976 Nutritional status: a determinant of severity of diarrhea in patients with cholera. J Infect Dis 134:8-14

4. Tompkins A 1981 Nutritional status and severity of diarrhea among preschool children in rural Nigeria. Lancet 1:860-862

5. Butler DG, Gall DG, Kelly MH, Hamilton JR 1974 Transmissible gastroenteritis: mechanisms responsible for diarrhea in an acute viral enteritis in piglets. J Clin Invest 53:1335-1342

6. Guiraldes E, Hamilton JR 1981 Effect of chronic malnutrition on intestinal structure, epithelial renewal, and enzymes in suckling rats. Pediatr Res 15:930-934

7. Kerzner B, Kelly MH, Gall DG, Butler DG, Hamilton JR 1977 Transmissible gastroenteritis: sodium transport and the intestinal epithelium during the course of viral enteritis. Gastroenterology 72:457-461

8. McClung HJ, Butler DG, Kerzner B, Gall DG, Hamilton JR 1976 Transmissible gastroenteritis: mucosal ion transport in acute viral enteritis. Gastroenterology 70:1091-1095

9. Shepherd RW, Gall DG, Butler DG, Hamilton JR 1979 Determinants of diarrhea in viral enteritis: the role of ion transport in the ileum in transmissible gastroenteritis in piglets. Gastroenterology 76:20-24

10. Miniats OP, Jol D 1978 Gnotobiotic pigs-derivation and rearing. Can J Comp Med 42:428-437

11. Dalquist A 1968 Assay of intestinal disaccharidases. Anal Biochem 22:99-107

12. Kelly MH, Butler DG, Hamilton JR 1972 Transmissible gastroenteritis in piglets: a model of infantile viral diarrhea. J Pediatr 80:925-931

13. Klemperer HG, Haynes GR 1968 Thymidine kinase in rat liver during development. Biochem J 108:541-546

14. Lowry OH, Rosenbrough NJ, Farr AL, Randall RJ 1951 Protein measurement with the folin phenol reagent. J Biol Chem 193:265-275

15. James WPT 1971 Effects of protein-caloric malnutrition on intestinal absorption. Ann NY Acad Sci 176:244-261

16. Romer H, Urbach R, Gomez MA, Lopez A, Perozo-Ruggeri G, Vegas ME 1983 Moderate and severe protein energy malnutrition in childhood: effects on jejunal mucosal morphology and disaccharidase activities. J Pediatr Gastroenterol Nutr 2:459-464

17. Brunser OB, Reid A, Monckeberg F, Maccioni A, Contreras I 1966 Jejunal biopsies in infant malnutrition: with special reference to mitotic index. Pediatr 38:605-612

18. Neutra MR, Marer JH, Mayoral LG 1974 Effects of protein-caloric malnutrition on the jejunal mucosa of tetracycline-treated pigs. Am J Clin Nutr 27:287-295

19. Hatch TF, Lebenthal E, Branski D, Krasner J 1979 The effect of early postnatal acquired malnutrition on intestinal growth, disaccharidases and enterokinase. J Nutr 109:1874-1879

20. Shepherd RW, Hamilton JR, Gall DG 1980 The postnatal development of sodium transport in the proximal small intestine of the rabbit. Pediatr Res $14: 250-253$

21. Henriques de Jesus C, Smith MW 1974 Sodium transport by the small intestine of new-born and suckling pigs. J Physiol 243:211-224

22. Hindmarsh JT, Kelby D, Ross B, Wiseman G 1967 Further studies on intestinal active transport during semistarvation. J Physiol 188:207-218

23. Pensaert M, Haelterman EO, Burnstein T 1970 Transmissible gastroenteritis of swine: virus-intestinal cell interactions. I. immunofluorescence, histopathology and virus production in the small intestine through the course of infection. Arch Gasamte Virustorschung 31:321-334

24. Shepherd RW, Butler DG, Cutz E, Gall DG, Hamilton JR 1979 The mucosa lesion in viral enteritis: extent and dynamics of the epithelial response to virus invasion in transmissible gastroenteritis of piglets. Gastroenterology 76:770-777 